AIAA-2004-34309

\title{
An Evaluation of the Discharge Chamber of the 30,000 Hr Life Test of the Deep Space 1 Flight Spare Ion Engine
}

\author{
Charles E. Garner,* Anita Sengupta,* and James G. Kulleck* \\ Jet Propulsion Laboratory \\ California Institute of Technology \\ Pasadena, $C A$ \\ Thomas M. Liu \\ Department of Aerospace Engineering \\ University of Michigan \\ Ann Arbor, MI
}

\begin{abstract}
A 30-cm-diameter ring cusp ion thruster built as a flight spare unit for the DS1 mission was operated for over 30,352 hours to determine the ultimate service life capability of this thruster design. Post-test examinations indicate that molybdenum films up to $10 \mathrm{um}$ in thickness were deposited inside the discharge chamber and that these films adhered well to the sputter containment mesh. The magnetic field internal to the engine was unchanged with respect to magnetic field measured prior to the start of the life test. Propellant isolators were destructively analyzed and test data validated that the isolators were performing properly at the end of the test.
\end{abstract}

\section{Introduction}

Ion propulsion has entered the era of application. In 1998, Deep Space 1 (DS1) was launched and by the end of its three-year mission had operated its ion propulsion system for 16,265 hours and processed 73 $\mathrm{kg}$ of xenon propellant (References 1-7). The success of this mission in validating ion propulsion for deep space missions contributed to the selection of ion propulsion for NASA's Dawn Discovery mission and has stimulated interest in ion propulsion for other NASA missions that require more operating lifetime and propellant throughput than was demonstrated on DS1.

\footnotetext{
* Member Technical Staff, Thermal and Propulsion Engineering Section

+ Graduate Department, Plasmadynamics and

Electric Propulsion Laboratory
}

For example, Dawn, the first NASA deep space science mission to use ion propulsion for primary propulsion, requires up to approximately $400 \mathrm{~kg}$ of xenon throughput for a Vesta and Ceres rendezvous mission of approximately ten years duration. This mission is planned for launch in June 2006 (Reference 8).

Ground testing to identify failure modes and establish the full operating lifetime capabilities of the thruster design used on DS1 were needed to manage the risk of using this technology and allow NASA to make the fullest use of ion propulsion to reduce future mission costs and enhance mission capabilities. Several life tests (Reference 9-11) were performed on thrusters over the course of the NASA Solar Electric Propulsion System Technology Applications Readiness (NSTAR) program ending with the Extended Life Test (ELT) (References 912). These long duration tests, combined with the DS1 flight experience make this thruster design one of the most extensively tested thruster designs,

Copyright ( 2004 by the American Institute of Aeronautics and Astronautics, Inc. The U.S. Government has a royalty-free license to exercise all rights under the copyright claimed herein for Governmental purposes. All other rights are reserved by the copyright owner. 
however the full life capability of this thruster had not been demonstrated through test.

An extended life test (ELT) was conducted over a five year period between 1998 and 2003 (References 12-13) and voluntarily terminated after 30,352 hours of operation. The primary purpose of the ELT was to determine the ultimate service life capability of the NASA 30-cm-ion thruster technology for application to future NASA missions. The objectives of the test were to characterize previously observed failure modes, identify unknown failure modes, and quantify thruster performance as a function of engine wear and throttle level.

The ELT thruster, called FT2 for the second flight thruster built under the NSTAR program, was operating nominally at approximately $1 \mathrm{~kW}$ upon termination of the ELT (Reference 13). Over the life test the thruster processed $235.1 \mathrm{~kg}$ of xenon propellant, and acquired several thousand hours of operation at each of the five different throttled conditions investigated. Several performance variations and wear processes were observed and monitored during the course of the test. Degradation processes included erosion of the discharge cathode keeper, ion optics grid sputter erosion, deposition of material in the neutralizer cathode, and deposition of material within the discharge chamber. Post-test inspection of the engine was initiated immediately following the test termination, to document wear and deposition internal and external to the thruster, ascertain causes of the wear, and to potentially discover any previously unknown wear processes or failure modes.

This paper summarizes the results of a post-test evaluation of the discharge chamber of an extended life test of the DS1 spare flight ion thruster (FT2). In particular, results are presented on the discharge chamber magnetic field measurements, films and film deposits, and the high voltage main isolator.

\section{ELT Thruster Design}

The ELT was conducted with the second Flight Thruster (FT2) built at Boeing Electron Dynamics Devices in Torrance, California for the DS1 mission (Reference 13). This 30-cm-diamter ring cusp thruster, based on a Glenn Research Center (GRC) design and developed for flight under the NSTAR program, has been extensively tested with over
58,000 hours of testing and in-flight operations to date. The thruster can operate over an input power range of 0.5 to $2.3 \mathrm{~kW}$. The thruster consists of a conical/cylindrical discharge chamber, a hollow cathode electron emitter in the discharge chamber, molybdenum ion optics, and an exterior neutralizer hollow cathode. The design employs a ring-cusp magnetic field created by three samarium-cobalt rings, one located at the back end near the discharge chamber cathode, one ring where the conical section joins to the cylindrical section, and a ring located on the cylindrical section near the screen grid. The magnets were thermally stabilized at 350 degrees $\mathrm{C}$ to provide margin from demagnetization for full power operation. A photograph of the ELT thruster is shown in Figure 1.

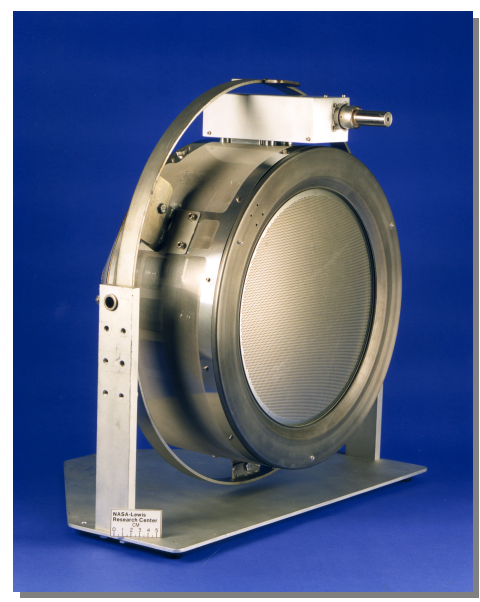

Figure 1. NSTAR Ion Thruster (FT2) used in the ELT.

The discharge chamber was fabricated from 0.48 -mm thick spun formed titanium and covered in the interior surface with a $0.1 \mathrm{~mm}$ thick stainless steel sleeve. A grit-blasted stainless-steel wire mesh was spot-welded to the stainless sleeve and to all surfaces in the interior of the discharge chamber excluding the cathode assembly.

\section{Thruster Test Facility}

The ELT was conducted in a 3-m diameter by $10-\mathrm{m}$-long stainless steel vacuum chamber with a total xenon system pumping speed of $100 \mathrm{~kL} / \mathrm{s}$ (Reference 12). The vacuum system provided a base pressure of less than 1.3E-10 atm (1E-7 Torr) and $5.3 \times 10-9$ atm $(4 \times 10-6$ Torr $)$ with the thruster operating at full power. Over the course of the almost five-year test there were 18 facility shutdowns necessitating cryopump shutdown and regeneration, 
but the vacuum chamber and ELT thruster were never exposed to atmosphere until the test was voluntarily terminated. The vacuum chamber was equipped with a residual gas analyzer (RGA) to monitor the presence and quantity of trace gases at high vacuum. A plot of residual gas composition over the first 29,000 hours of the ELT is shown in Figure 2 .

The chamber was lined with graphite panels to reduce the amount of material back sputtered onto the engine and test diagnostics. Quartz crystal microbalances (QCM) were placed next to the engine in two locations, and provided real time measurements of back sputtered material in the plane of the grids. The measured backsputter deposition rate, monitored with a quartz crystal microbalance (QCM) mounted next to the engine in the plane of the grids, was $0.16 \mathrm{mg} / \mathrm{cm} 2 \mathrm{khr}$ or $0.7 \mu \mathrm{m} / \mathrm{khr}$ at full power. Several diagnostics were used to measure the ion beam characteristics as well as general engine performance parameters. The diagnostics included a thrust stand, ExB probe, thrust vector probe, faraday probe, video camera system, LASER profilometer, and retarding potential analyzer (Reference 12). Indepth details of the test facility, electrical system and details on the operation and design of the diagnostics can be found in References 14-16.

\section{Thruster Test Plan}

The ELT thruster is designed to be throttleable over a range of thruster input power of 0.5 to $2.3 \mathrm{~kW}$. The DS1 thruster utilized a total of 50 "mission levels" and 16 throttle levels (Reference 3), however for the ELT, 16 throttle points were chosen, to facilitate testing. The throttle table used a $\mathrm{TH}$ designation for each operating point, with a power range of $0.5 \mathrm{~kW}$ (TH0) to $2.3 \mathrm{~kW}$ (TH15), the minimum and full power points respectively. The beam current and voltage were controlled to provide different fixed levels of thrust and specific impulse. For each throttle point, flow rates were set to account for tank ingestion, and to maintain a discharge chamber propellant efficiency of approximately $90 \%$. The neutralizer flow rate was set to minimize cold flow losses, whilst providing sufficient margin from plume mode operation.

The ELT thruster was operated at four different throttle points for approximately 5000 to 6000 hour intervals each, and one throttle level for $500 \mathrm{hrs}$ ) to investigate wear and failure as a function of power level. The thruster was operated at $2.3 \mathrm{~kW}$ (TH15) for three test segments for a total of approximately 14,000 hours, at $1.46 \mathrm{~kW}$ (TH8) for one test segment, for 5500 hours at $0.5 \mathrm{~kW}$ (TH0) for one test segment for 5700 hours, and at $1.1 \mathrm{~kW}$ (TH5) for the final 4646 hours. There was an emphasis on full power operation to maximize throughput, and because accelerator grid wear is most significant at this level. Operation at $0.5 \mathrm{~kW}$ (TH5) and $1.46 \mathrm{~kW}$ (TH8) were specifically chosen to understand neutralizer performance degradation at the lower power levels, previously observed during TH0 operation.

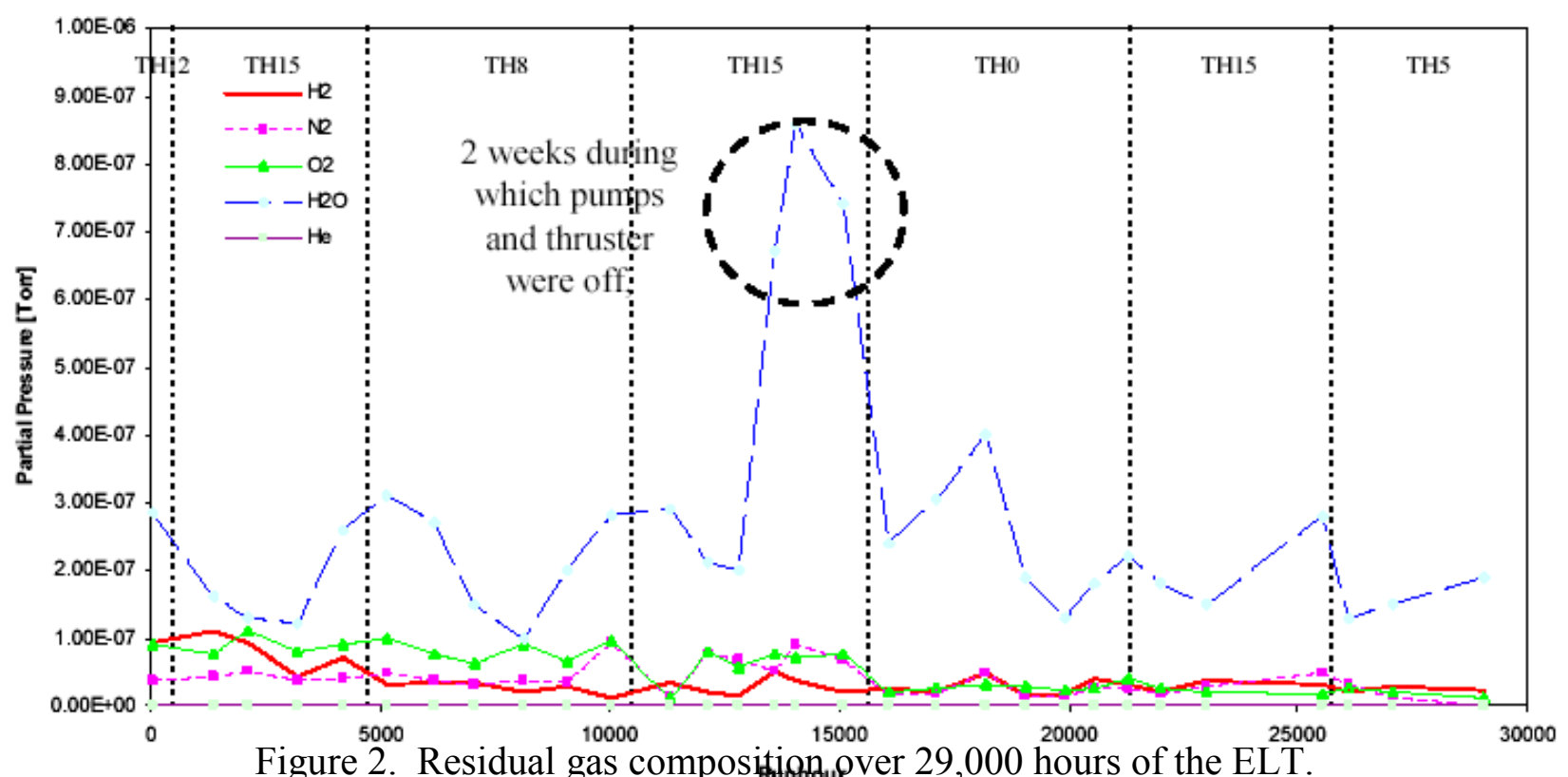

Figure 2. Residual gas composition ${ }^{2}$ pver 29,000 hours of the ELT. 
During each test segment, thruster electrical parameters were monitored and recorded every 5 seconds. The location of the thrust vector was recorded every five minutes, and performance data were obtained every 100 to 200 hours. Throttle tests, neutralizer characterizations, and sensitivity tests were performed every 2000 to 3000 hours, to investigate thruster performance and the effects of wear over the full throttle range. Video and photographic data of the neutralizer and discharge cathode assemblies, and downstream face of the accelerator grid was taken every 1000 to 2000 hours, to monitor and quantify erosion processes. A summary of the ELT is provided in Reference 12.

The post-test analyses were initiated immediately following final engine shutdown on June 26, 2003. The destructive analyses are being performed at the component level, specifically documenting wear and deposition sites for the discharge chamber and specific locations external to the discharge chamber (Reference 12). Wear is quantified by a combination of optical inspection, scanning electron microscope (SEM) inspection, Energy Dispersive Spectroscopy (EDS) analysis, and both non-contact and contact physical measurements.

\section{Results}

\section{Magnetic Field Maps}

The magnetic fields generated by the samarium cobalt magnet rings were measured internally and externally to the discharge chamber. External magnetic field measurements, made at the conclusion of the ELT using a Helmholtz coil and magnetometer boom, are shown in Figure 3. Comparison of this data to pre-test data is still underway.

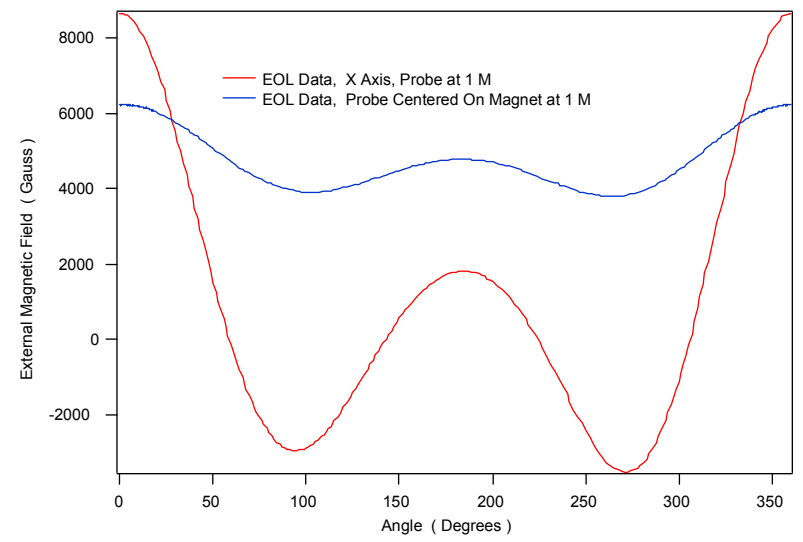

Figure 3. Post-test external magnetic field data of the FI .T thruster.
A gauss meter was used to measure the internal magnetic field of the engine after the grids were removed. The internal magnetic filed was mapped with a spatial resolution of a minimum of $1 \mathrm{~cm}$ or less, up to within $1 \mathrm{~cm}$ of the walls of the discharge chamber. In all cases the standard deviation of magnet values was under 3\%. The ELT thruster internal magnetic field was mapped pre-test at GRC (Reference 17) and is the data used to determine changes to the magnetic fields pre and post-test. Every effort was made to define an identical "zero" axial location for both pre and post-test data, which in this case is defined as the center of the cathode orifice plate.

Figure 4 is a plot of the centerline magnetic field strength at BOL and after 30,352 hours of operation. BOL data from Reference 17 taken at GRC were used as a baseline to identify any changes over the test. Centerline "zero" is defined as the center of the keeper electrode. The data indicate that there was no measurable degradation in the internal discharge chamber magnetic circuit throughout the interior of the discharge chamber, which corresponds to the absence of change in the discharge performance from BOL.

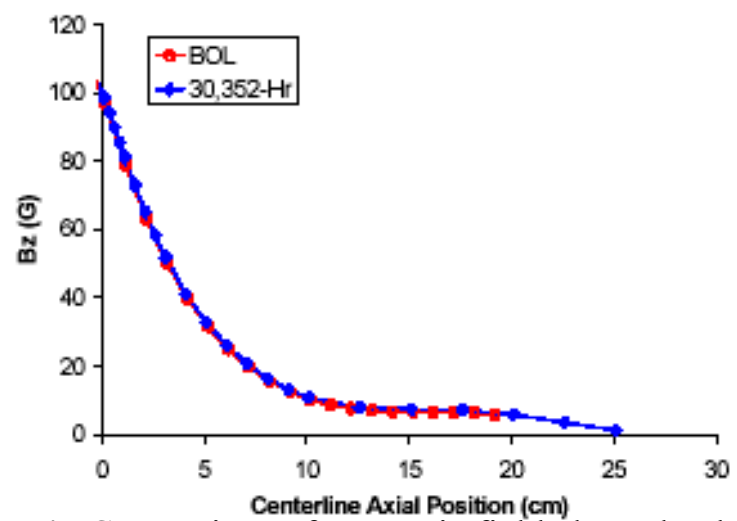

Figure 4. Comparison of magnetic field along the thruster axis for BOL and end of test.

\section{Main High Voltage Isolator}

Post-test inspection of the main high voltage isolator was performed to determine any possible degradation in isolator performance from BOL. High voltage vacuum testing was performed to measure breakdown voltage as a function of upstream internal pressure. A range of upstream pressures, 
representative of the full flow rate throttle range, was investigated. Comparison of the $30,000-\mathrm{hr}$ isolator and an unused control isolator of the same design indicated virtually identical breakdown performance over the full range of pressures. The data are shown in Figures 5-6.

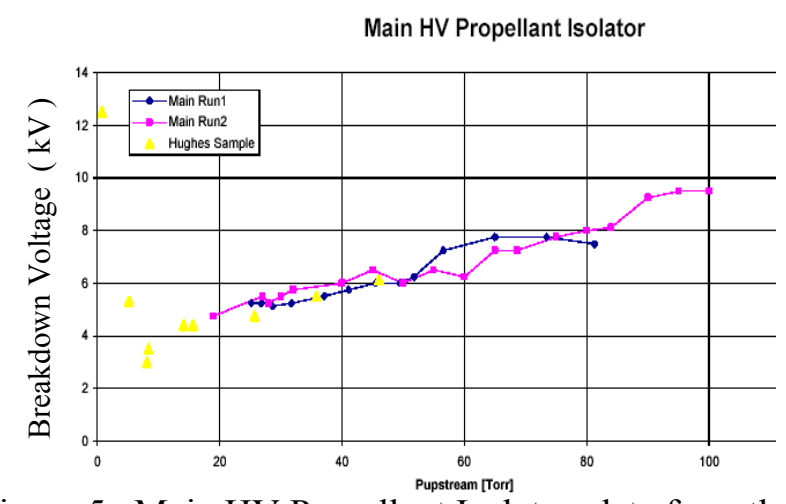

Figure 5. Main HV Propellant Isolator data from the ELT.

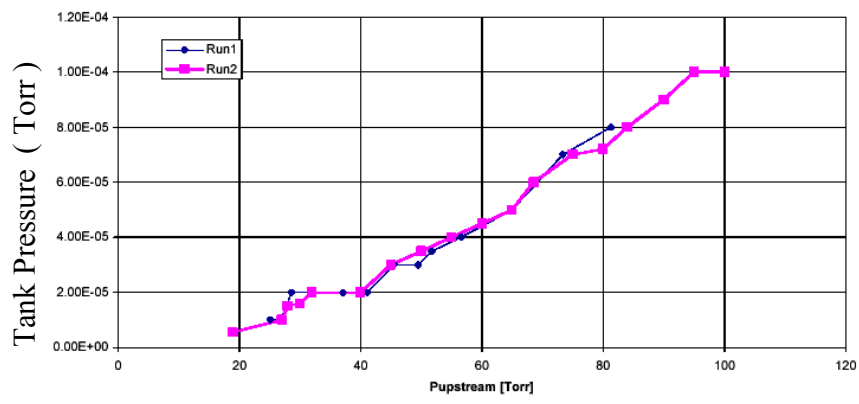

Figure 6. Main HV Propellant Isolator data from the ELT.

\section{Discharge Chamber Flake Analysis}

Post-test inspection of the discharge chamber following the ELT revealed the presence of numerous small flakes on the surface of the sputter containment mesh. The flakes were located at the bottom of the discharge chamber in an arc between approximately the 4:00 to 8:00 o'clock positions, viewed from the grid end of the thruster. The flakes were then swept into 18 separate piles using fine brushes and collected separately so that data on flake type could be correlated to collection location. Flakes that could not be collected via brushes were collected using Teflon tape. A diagram showing where flakes were collected is shown in Figure 7.

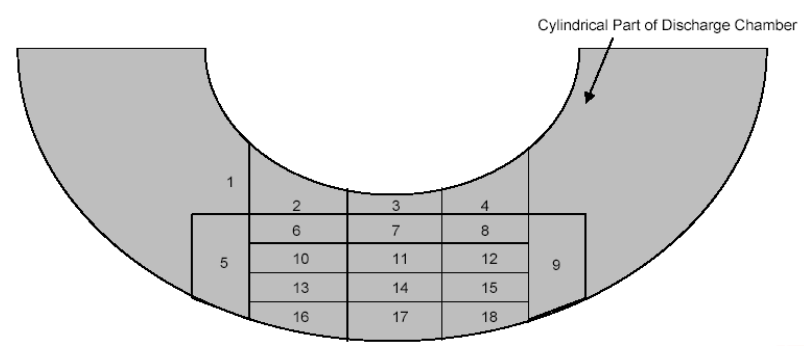

Figure 7. Zones in the discharge chamber for flake collection.

Films collected off of external surfaces such as the front mask were collected and film thicknesses were measured. Films such as those shown in Figure 8 from the front mask were up to approximately 50 microns in thickness and consisted mostly of carbon, likely sputtered from the graphite beam target at the back of the vacuum chamber. A list of samples and from where they were collected is shown in Table 1.

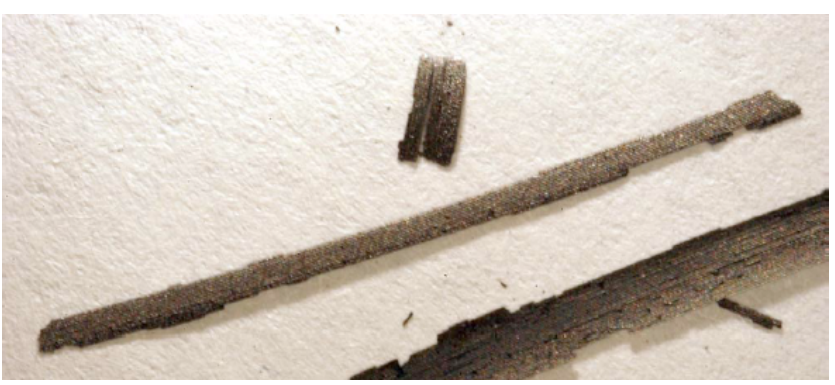

Figure 8. Carbon deposit collected from the downstream face of the thruster front mask.

An SEM of a typical set of flakes collected from the bottom of the discharge chamber is shown in Figure 9. In this particular sample the dark grainy surface of the flake in the center of the SEM is rich in carbon, as determined by energy dispersive spectroscopy (EDS) analysis which determines qualitatively the elemental content of the sample within a few tens of angstroms of the surface, but the lighter colored pieces located next to it are rich in molybdenum (again determined via analysis). From visual inspection and EDSanalysis it appears that most flakes are a mixture of mostly carbon and molybdenum. 
Table 1. List of samples collected from ELT

Description

Discharge Chamber Flakes Area 1

Discharge Chamber Flakes Area 2

Discharge Chamber Flakes Area 3

Discharge Chamber Flakes Area 4

Discharge Chamber Flakes Area 5

Discharge Chamber Flakes Area 6

Discharge Chamber Flakes Area 7

Discharge Chamber Flakes Area 9

Discharge Chamber Flakes Area 10

Discharge Chamber Flakes Area 14

Front Screen, 6:00 Position

Downstream Accel Grid

Plasma Screen, 1:30 Position

Plasma Screen, 4:00 Position

Plasma Screen, 6:00 Position

Front Neutralizer Cover, Left Side, Top

Cathode End of Plasma Screen, 12:00

Top of Doghouse

Door Flakes

Thrust Stand Support, West End

Top of Antenna Box

Edge of Plasma Screen, 4:00 Position

LN2 Shroud, bottom

Low Flow Neutralizer Support

Loose Debris from Top of Neutralizer Box

Midpoint of Bottom of Discharge Chamber

Bottom of Front Mask

Midpoint of the Disch Chamber, $2 \mathrm{~cm}$ from

Screen Grid

Antenna Flakes

Bottom of Plasma Screen
Mass, mg

0.1

2.5

3.3

0.9

$<0.1$

1.2

3.5

$<0.1$

1.8

7.5

5.7

0.8

28.1

3.8

11.6

3.8

0.3

$<0.1$

1.1

0.4

$<0.1$

1.6

120.6

1.8

1.2

$<0.1$

33.6

1.9

9.9

4.9

The majority $(>60 \%)$ of the flakes were less than $0.1 \mathrm{~mm}$ in length, although a few large flakes (less than $1 \%$ ) were on the order of $1 \mathrm{~mm}$ in length. SEM analysis of the less than $0.1 \mathrm{~mm}$ long cross-sectioned flakes revealed multiple layers of molybdenum and carbon. The atomic composition of the flakes ranged from 40 to $70 \%$ carbon, and $1-30 \%$ molybdenum, with trace amounts of tantalum and stainless steel depending upon the location where the flake was collected.

The source of molybdenum was likely sputter erosion of the discharge side of the screen grid, and the discharge keeper electrode plate. Some samples had substantial tantalum content that may have been sputtered from the tantalum keeper tube and discharge cathode heater (Reference 12). Chrome and iron may have come from the stainless-steel sputter containment mesh and the test facility. Although the flakes were multi-compositional, the majority were in the greater than $70 \%$ carbon composition range, suggesting the flakes are a facility induced effect, and would not have formed if the engine were operated in space (Reference 12). Carbon deposition found to be on many of the thruster's interior and exterior surfaces is a direct result of re-deposition of sputter eroded carbon atoms from the graphite panels that line the chamber. A crude total mass estimate of the flakes found on the bottom of the discharge chamber is $21 \mathrm{mg}+/-5 \mathrm{mg}$, neglecting samples collected using Teflon tape. A detailed analysis of some of the flakes collected from the discharge chamber is presented in Reference 18.

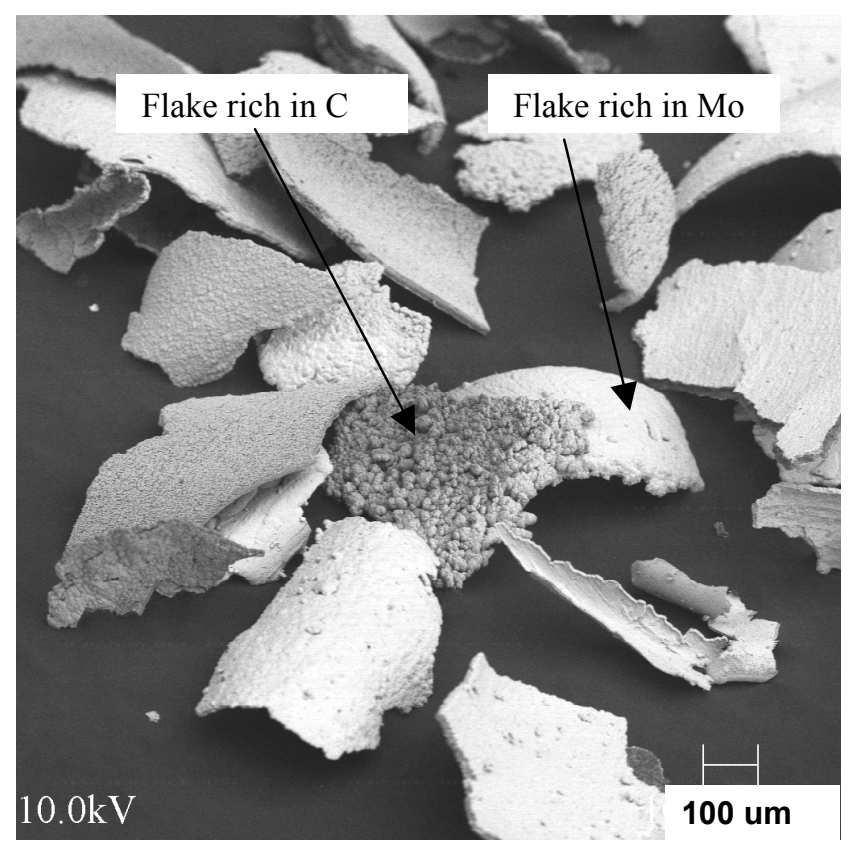

Figure 9. Flakes collected from the discharge

Few of the samples collected were of sufficient size to bridge the gap between the screen and accel grids. However, a few samples collected from the discharge chamber appeared as long thin tubes, as shown in Figure 10. EDS analysis indicates that these samples are molybdenum-coated fiberglass fibers, likely from the insulation used in the internal wiring of the thruster (but used external to the discharge chamber). Fibers that slough off the thruster wiring and wind up in the discharge chamber could become sputter-coated with sufficient molybdenum over time, spall and if of sufficient size 
to bridge the gap between the screen and accel grids could cause a screen/accel grid short. Future missions may have to re-evaluate use of this type of wiring insulation.

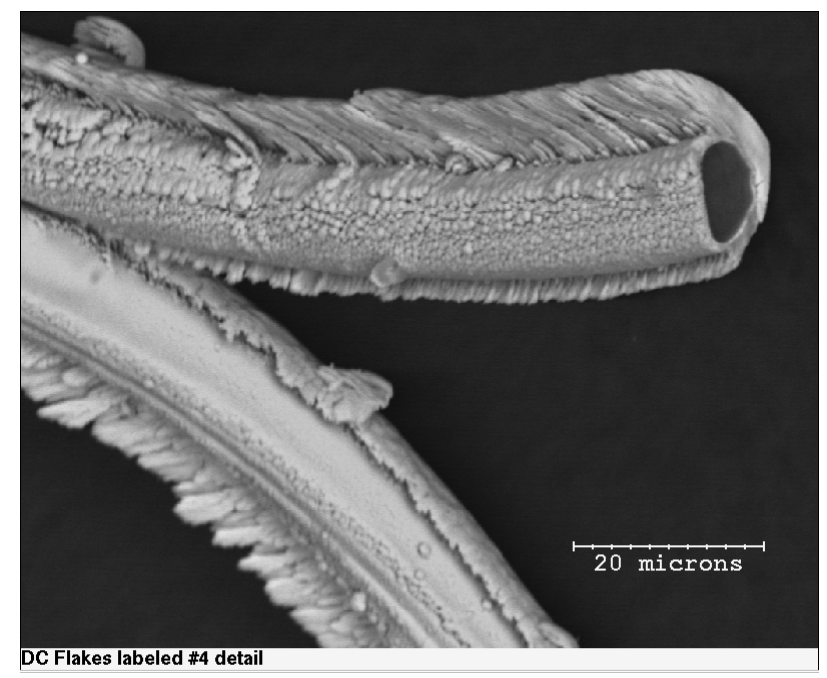

Figure 10. Molybdenum-coated fiberglass strands found in the ELT discharge chamber.

\section{Films Analysis}

Post-test analysis was made on the films adhering to the sputter containment mesh to characterize the thickness and composition of the films and identify problem areas where film thicknesses are excessive or where films have spalled. The sputter containment mesh is a woven and grit-blasted stainless steel fiber mesh, designed to collect and retain sputter deposited material thereby preventing the formation and release of flakes that might otherwise cause a grid-to-grid short or roguehole formation. The mesh is spot-welded to a 0.1 mm-thick stainless steel shell that covers the interior of the discharge chamber. Except for the cathode and keeper assemblies, mesh covers all of the chamber wall surfaces including rivet heads.

Samples of the mesh (approximately $1 \mathrm{~cm}^{2}$ in size) from different azimuthal and axial locations inside the engine's discharge chamber, still bonded to the underlying steel shell, were laser-cut or mechanically removed from the thruster using a cutting tool. A diagram of sample removal locations is shown in Figure 11.

After removal the samples were placed in an SEM, photographed, and surface elemental composition of the adherent films was determined using backscatter x-ray or EDS analysis. Then the samples were epoxied, polished and viewed in the SEM to determine film properties and thickness. A photograph of the discharge chamber with samples removed is shown in Figure 12. The damaged area near the bottom of the photograph is damage caused by improper laser cutting at that location.

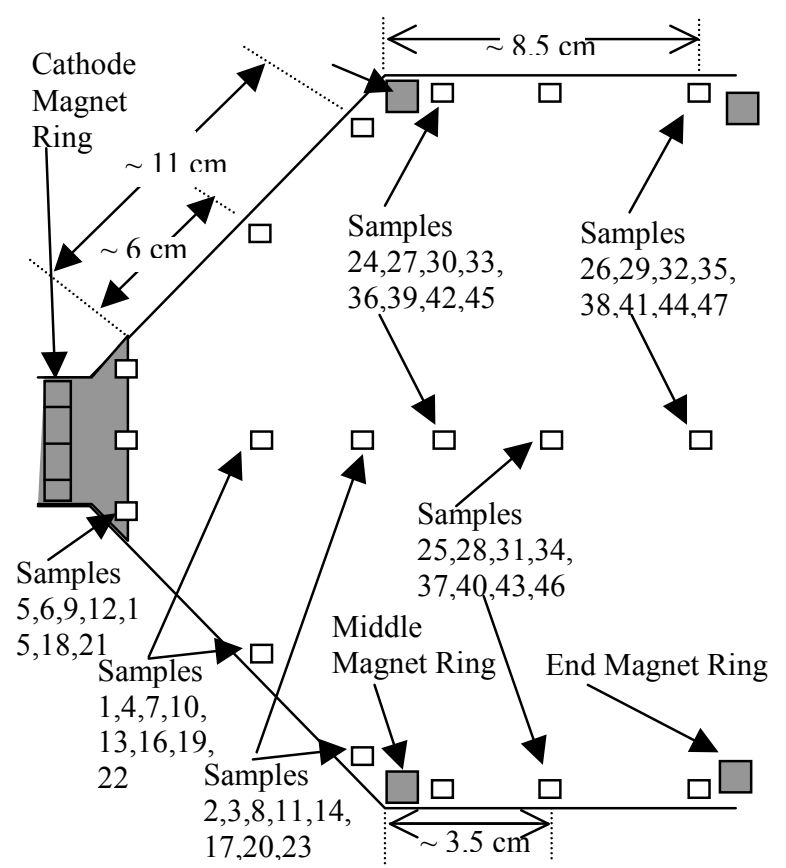

Figure 11. Diagram of sample locations from the discharge chamber of the ELT thruster.

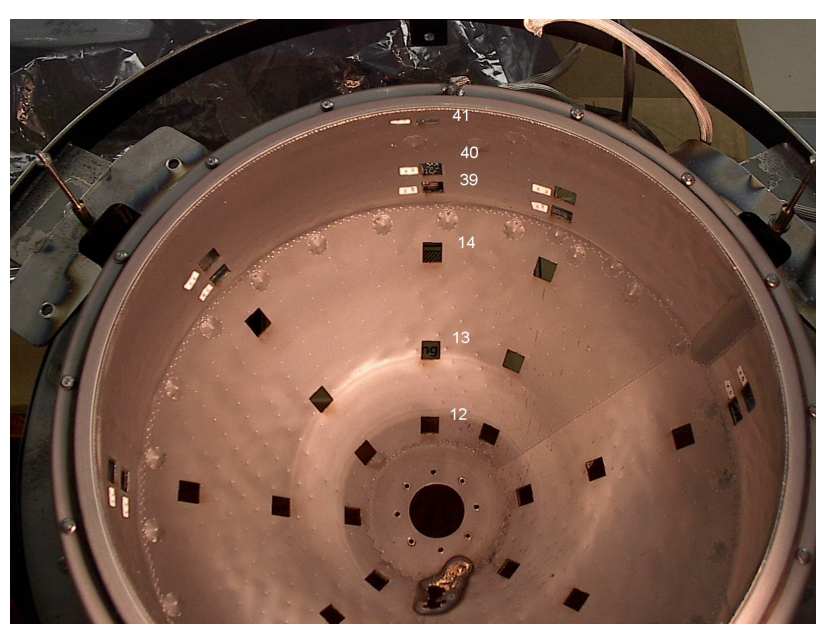

Figure 12. Photograph showing discharge chamber after samples were removed via laser-cutting.

Analysis of the sputter containment mesh indicates the presence of deposits with varying 
thickness and composition as a function of distance from the screen grid electrode. SEM analysis indicates the deposits are 5 microns thick near the cathode (samples 9 and 12) and 10 microns thick near the screen grid (samples 38 and 41). A list of sample locations and film thicknesses for a row of holes (Figure 12) is shown in Table 2.

Photographs of adhered films are shown in Figures 13-18. The films appear to have adhered very well to the mesh in all locations except where flake samples were removed from the discharge chamber (Figures 19-20). SEM photographs indicate that only samples \#36, 37 and 38, which were taken from the cylindrical portion of the discharge chamber where flakes were collected, had spalled films. It is likely that at these locations the films were spalled from handling.

There is no apparent azimuthal variation in thickness for a given axial location. Inspection of the deposited films indicate that they had not yet bridged the gaps between the weave, a criteria used for the adequate retention of sputter deposited films. All of the films have a striated look with dark and light bands when viewed from the side. EDS analysis indicates the dark areas are rich in carbon and the light areas are rich in molyndenum. The carbon is likely from the beam target that was located some 8 meters from the ion thruster.

Samples located nearest the screen grid generally exhibited lesser amounts of carbon in the layers compared to samples taken from regions of the thruster where there was a more direct line-of-sight to to the beam target. It appears that the rate of carbon getting into the thruster from the beam target relative to the molybdenum sputtered from the screen grid changed over the course of the test, resulting in the layers observed in the SEM photographs. These carbon layers will affect how well the molybdenum films adhere to the sputter containment mesh.

\section{Summary}

Post-test inspection indicates the discharge chamber experienced minimal sputter erosion. Molybdenum/carbon flakes with some tantalum were present on the sputter containment mesh. Tantalum was more prevalent on samples that were located nearest to the cathode. It is believed that the bulk of the flakes are due to back sputtered beam target material, coated by sputter eroded grid material, a facility induced effect, and to flake collection which took place between the 4:00 and 8:00 0'clock positions of the screen grid (viewed from the front of the thruster). The thickness of the flakes collected from the discharge chamber and the facility varied from a few microns to approximately 50 microns for samples collected from the front face of the front mask. Samples cut from the discharge chamber walls were evaluated for composition and thickness. SEM indicate that the films, composed primarily of molybdenum, tantalum, and carbon, adhere very well to the sputter containment mesh. Internal magnetic field maps made post-test indicated that the peak magnetic field near the downstream face of the discharge cathode did not change, demonstrating that the magnets did not degrade

Table 2. Sample Location, Film Thickness and Surface Composition

\begin{tabular}{|c|c|c|c|}
\hline Sample Location & $\begin{array}{l}\text { Sample } \\
\text { Number }\end{array}$ & Thickness & $\begin{array}{l}\text { Elemental Analysis } \\
\text { Mo \% Ta \% }\end{array}$ \\
\hline & & um & \\
\hline Nearest cathode & 12 & 5.8 & 84.6 \\
\hline Mid-conical section & 13 & 5.6 & 1.4 \\
\hline Conical/cylindrical interface & 14 & 6.4 & 96.7 \\
\hline Nearest middle magnet ring & 39 & 6.9 & 96.9 \\
\hline Near middle of cyl. section & 40 & 9.9 & 97.6 \\
\hline Nearest to screen grid & 41 & 9.3 & 97.7 \\
\hline Nearest cathode & $\begin{array}{ll}9 & 12\end{array}$ & 5.8 & \\
\hline Mid-conical section & $10 \quad 13$ & 5.6 & \\
\hline Conical/cylindrical interface & 1114 & 6.4 & \\
\hline Nearest middle magnet ring & $36 \quad 39$ & 6.9 & \\
\hline Near middle of cyl. section & $37 \quad 40$ & 10.0 & \\
\hline Nearest to screen grid & 3841 & 9.3 & \\
\hline
\end{tabular}




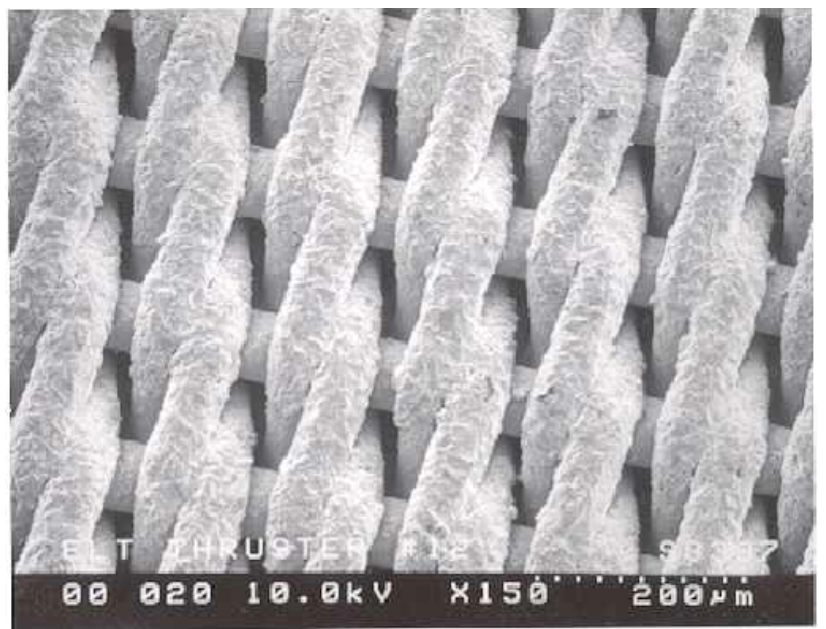

Figure 13. Sample \#12 nearest cathode magnet ring.

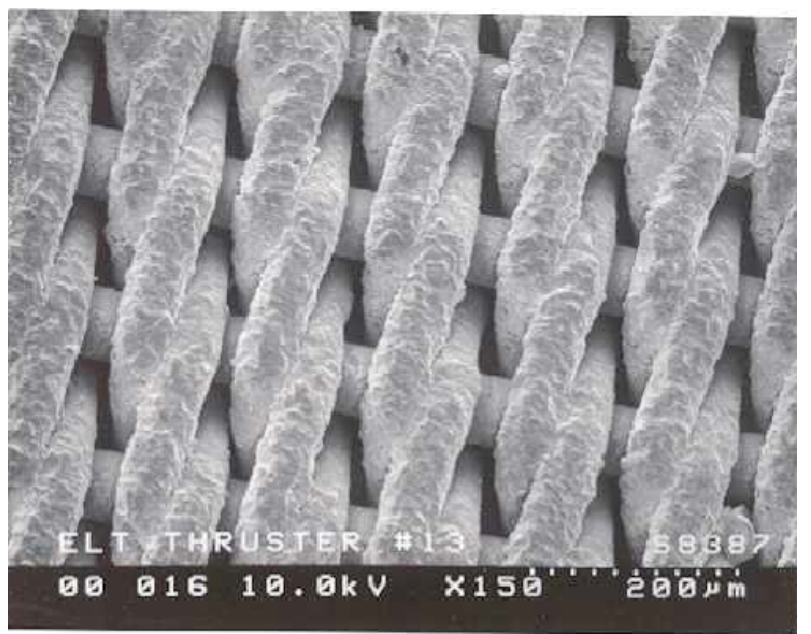

Figure 14. Sample \#13 in the conical section of the discharge chamber.

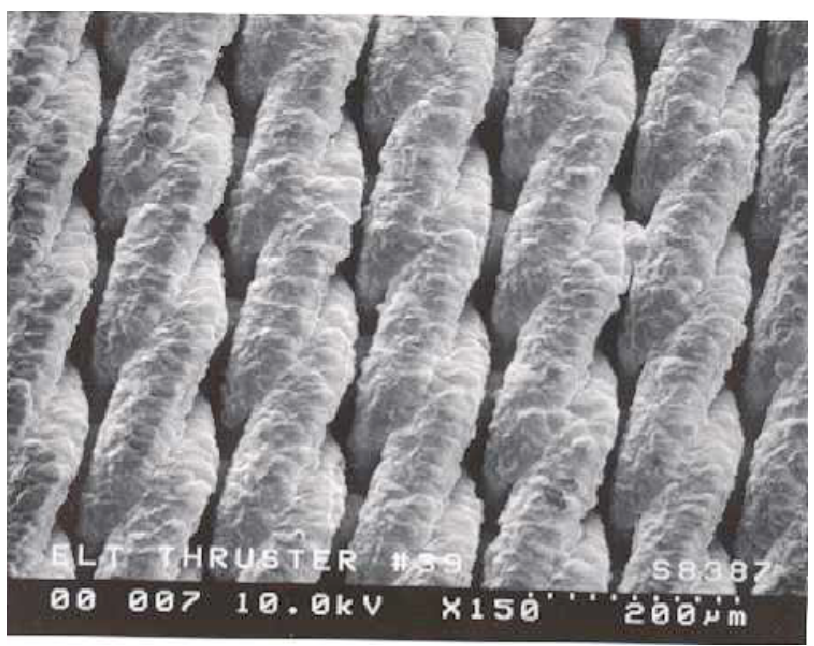

Figure 16. Sample \#39 nearest mid-magnet ring.
Figure 15. Sample \#14 near the cone/cylindrical

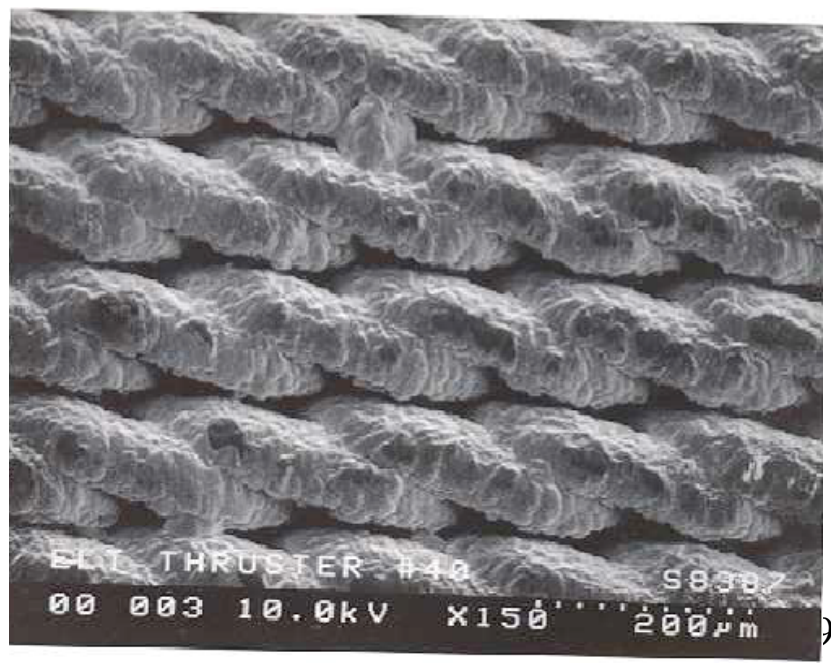

Figure 17. Sample \#40, midway in the cylindrical portion of the discharge chamber.
Figure 18. Sample \#41 nearest screen grid. 


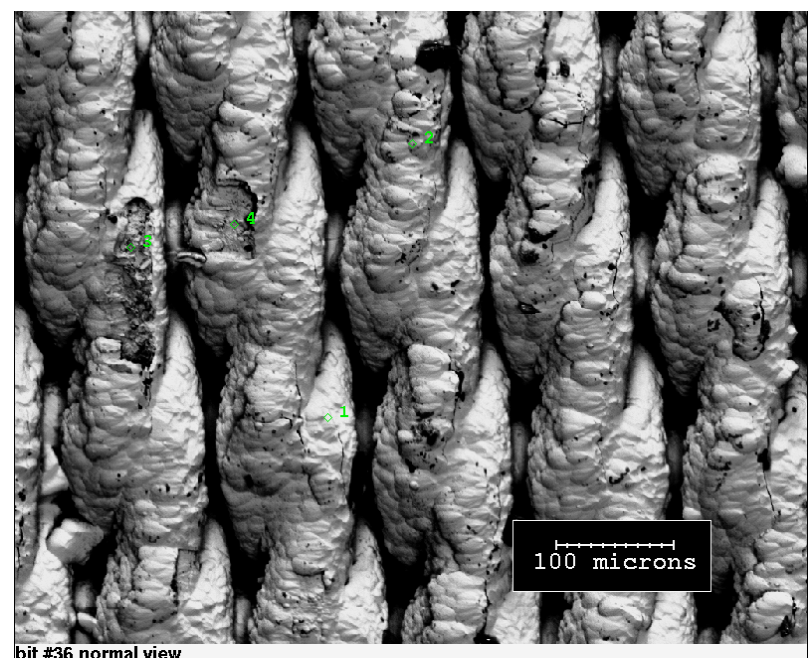

Figure 19. Sample \#37 SEM indicates that films have spalled from the mesh. This sample was taken midway in the cylindrical portion of the discharge chamber.

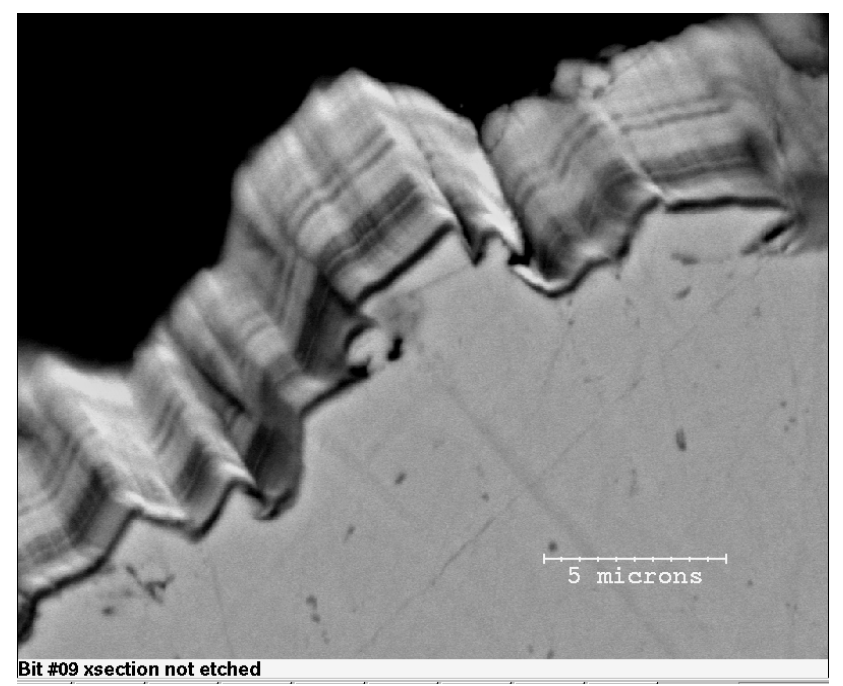

Figure 21. Film layer seen edge on from sample \#9, taken from an area nearest the cathode.

over the duration of the test. The data bode well for a re-evaluation of the assumed maximum service life of this thruster design.

\section{Acknowledgements}

The authors gratefully acknowledge the assistance of Ken Evans, Ron Ruiz and Alison Owens for their assistance in extracting and evaluating the samples for this work. The work

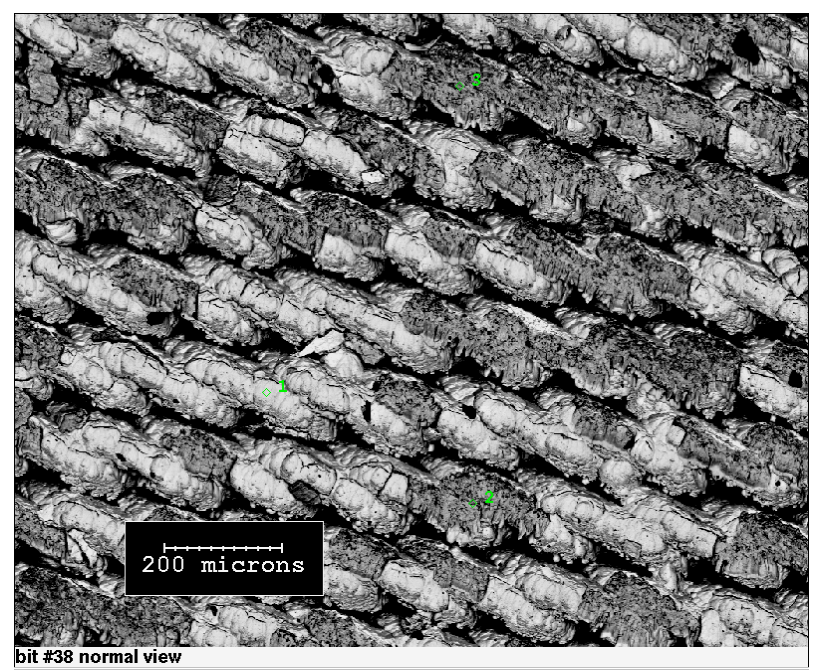

Figure 20. Sample \#38 SEM indicates that films have spalled from the mesh. Sample was located nearest the screen grid.

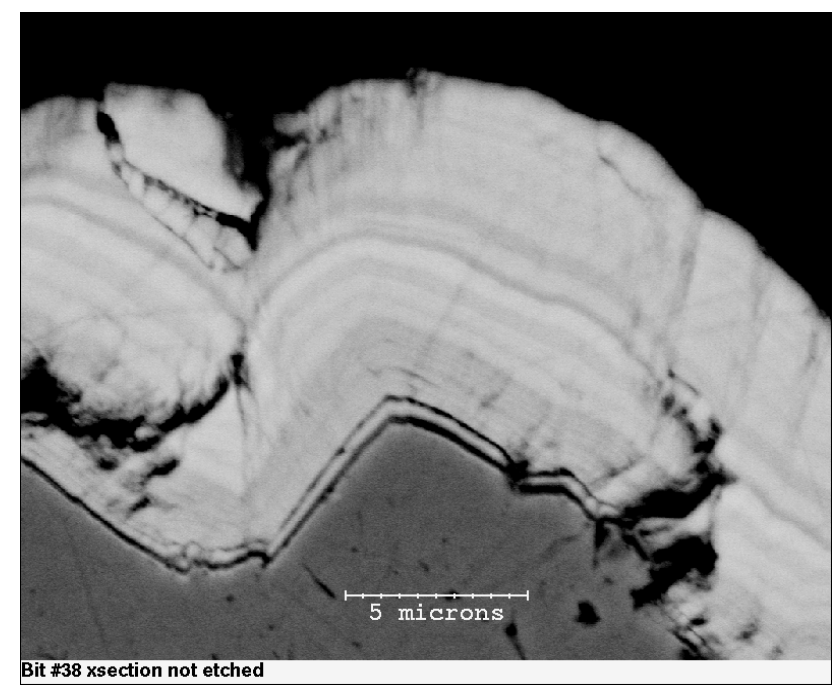

Figure 22. Film layer from sample \#38, which was located closest to the screen grid.

described in this paper was conducted, in part, by the Propulsion Laboratory, California Institute of Technology, under contract to the National Aeronautics and Space Administration. Funding was provided by the In-Space Propulsion Program managed by Jim Robinson at NASA Headquarters, Office of Space Science. The ELT project is managed by Randy Baggett of NASA Marshall Space Flight Center. Their support is gratefully acknowledged. 


\section{References}

1. M. D. Rayman, P. Varghese, D. H. Lehman, and L. L. Livesay, "Results From The Deep Space 1 Technology Validation Mission," IAA-99IAA.11.2.01, Presented at the 50th International Astronautical Congress, Amsterdam, The Netherlands, 4-8 October, 1999, Acta Astronautica 47, p. 475 (2000).

2. M. D. Rayman and P. Varghese, "The Deep Space 1 Extended Mission," Acta Astronautica 48, No. 5-12, pp. 693-705 (2001).

3. Polk, J.E. et al., "Demonstration of the NSTAR Ion Propulsion System on the Deep Space One Mission", $27^{\text {th }}$ International Electric Propulsion Conference, October 2001.

4. Brophy, J. R., et al., "Ion Propulsion System (NSTAR) DS1 Technology Validation Report," JPL Publication 00-10, October 2000.

5. J. E. Polk, et al., "Validation of the NSTAR Ion Propulsion System on the Deep Space One Mission: Overview and Initial Results," AIAA 99-2274, presented at the 35th Joint Propulsion Conference and Exhibit, 20-24 June 1999, Los Angeles, California.

6. J. E. Polk, et al., "Demonstration of the NSTAR Ion Propulsion System on the Deep Space One Mission, IEPC-01-075, Presented at the 27th International Electric Propulsion Conference, Pasadena, CA, 15-19 October, 2001.

7. Brophy, J. R., Brinza, D. E., Polk, J. E., Henry, M. D., and Sengupta, A., "The DS1 HyperExtended Mission, AIAA-2002-3673, presented at the 2002 Joint Propulsion Conference, Indianapolis, IN, July 7-10, 2002.

8. Brophy, J.R. et al., "The Ion Propulsion System for Dawn," AIAA-2003-3942, Joint Propulsion Conference, Huntsville, Alabama, July 2003.

9. Polk, J.E. et asl., "A 1,000-Hour Wear test of the NASA NSTAR Ion Thruster," AIAA-96-2717, July 1996.

10. Polk, J.E. et al., "The Effect of Engine Wear on Perfformance in the NSTAR 8000 Hour Ion Engine Endurance Test," AIAA-97-3387, July 1997.

11. Sengupta, A., Brophy, J. R., Goodfellow, K. D., "Status of the Extended Life Test of the Deep Space 1 Flight Spare Ion Engine after 25,700 Hours of Operation," AIAA-2003-4558, to be presented at the 2003 Joint Propulsion Conference, Huntsville, AL, July 20-23, 2003.
12. Sengupta, A. et al., "An Overview of the Results from the 30,000 Hr Life Test of Deep Space 1 Flight Spare Ion Engine," $40^{\text {th }}$ AIAA/ASME/SAE/ASEE Joint Propulsion Conference and Exhibit, AIAA-2004-3609, Ft. Lauderdale, Florida, July 2004.

13. Christensen, J. et al., "Design and Fabrication of a Flight Model $2.3 \mathrm{~kW}$ Ion Thruster for the Deep Space 1 Mission," AIAA-98-3327, July 1998.

14. Sengupta, A., et al, "Status of the Extended Life Test of the Deep Space 1 Flight Spare Ion Engine After 30,352 Hours of Operation," AIAA-20034558, July 2003.

15. Sengupta, A., et al, "Performance Characteristics of the Deep Space 1 Flight Spare Ion Thruster Long Duration Test After 21,300 Hours of Operation “, AIAA-2002-3959, July 2002.

16. Anderson, J. R., et al., "Results of an On-going Long Duration Ground Test of the DS1 Flight Spare Ion Engine," AIAA-99-2857, June 1999.

17. Sovey, J.S., NSTAR Report EDT 7a, August 2000.

18. de Groh, K.K. et al., "NSTAR Extended Life Test Discharge Chamber Flake Analysis," AIAA-2004-3612, Ft. Lauderdale, Florida, July 12-15, 2004. 